Revista de Antropología Social

ISSN: 1131-558X

\title{
La construcción de lo indecible: chisme, dato y etnografía en un contexto policial argentino
}

Mariana Sirimarco ${ }^{1}$

Recibido: 15 de marzo de 2016 / Aceptado: 19 de marzo de 2017

Resumen: Gluckman señaló, hace tiempo, que una parte importante de ganar la membresía a un grupo es aprender sus escándalos: aprender que hay cosas que pueden decirse y cosas que no. ¿Qué sucede cuando, en el trabajo de campo, el antropólogo se topa con una información que es un chisme pero también puede ser un dato? ¿Cuándo y por qué se alcanza el límite de lo decible? Este trabajo aborda un episodio sucedido en el contexto de mi trabajo de campo en una escuela policial argentina, con la intención de reflexionar en torno a la antropología y su relación con la producción de conocimiento, y de desnudar las tensiones entre lo que el etnógrafo sabe, lo que se le permite saber y lo que alcanza finalmente el texto de la etnografía.

Palabras clave: Chisme; dato antropológico; conocimiento; etnografía; policía.

[en] The unsayable: gossip, data and ethnography in an Argentinean police context

\begin{abstract}
Some time ago, Gluckman stated that a most important part of gaining membership to a group is to learn its scandals: what you can say and what you may not. So, what happens during fieldwork when the anthropologist bumps into a piece of information that is considered gossip but it can also be considered data? When and why we reach the limit of what can be said? This paper addresses an episode that took place during my fieldwork in an Argentinean police school, with the aim of reflecting on the anthropological practice and its production of knowledge, and of undressing the tensions between what the ethnographer knows, what he is let to know and what it finally reaches the ethnographical text.
\end{abstract}

Keywords: Gossip; anthropological data; knowledge; ethnography; police.

Sumario. 1. Introducción. 2. El caso. El chisme. 3. El caso. El dato. 4. El chisme. El dato. La etnografía. 5. Referencias bibliográficas.

Cómo citar: Sirimarco, M. (2017). La construcción de lo indecible: chisme, dato y etnografía en un contexto policial argentino, en Revista de Antropología Social 26(1), 53-72.

\section{Introducción}

De 1999 a 2004 hice trabajo de campo en dos escuelas policiales de la Argentina: la Escuela de Suboficiales y Agentes de la Policía Federal Argentina (PFA) y la Escuela

\footnotetext{
1 Investigadora Adjunta Conicet-Universidad de Buenos Aires. maikenas@yahoo.com.ar
} 
de Policía de la Policía de la Provincia de Buenos Aires (PPBA) ${ }^{2}$. El extenso trabajo de campo me llevó a compartir espacios, charlas y experiencias con profesores y alumnos: desde aulas a asados de fin de año, desde viajes conjuntos a innumerables tazas de café.

La largura y regularidad del tiempo compartido generaron, luego de un tiempo inicial de recelo ${ }^{3}$, lazos y relaciones de cotidianeidad. Mi presencia era esperada y buscada en clases y pasillos. Mis ausencias o demoras eran subrayadas con algo cercano a la pena por la falta. Mi estar ahi se volvió acostumbrado y requerido. Y hasta mi libreta de campo - para echar mano a un ejemplo cotidiano pero esclarecedorse transformó en un objeto co-construido que los alumnos utilizaban para refrescar lo visto la clase anterior, para disputar la autoridad docente (corroborando si éste había hecho referencia o no a cierta temática) y hasta para chuzar a un compañero que había dicho algo comprometido a la voz de "anote, doctora" mente: había llegado a ese punto del trabajo de campo en que la aceptación sucede.

Y con esa aceptación llegó, entonces, un hecho aparejado. Una tarde, después de clase, me había quedado charlando con Alejandra, una de las profesoras de la escuela. Dictaba una materia humanística y, además de docente en esa escuela, trabajaba en una Secretaría del Ministerio de Seguridad. Tenía, por consiguiente, varias amistades y conocidos en el mundo policial, aunque ella misma no era policía.

Esa tarde hablábamos del personal de la escuela, de la disciplina que excedía a los alumnos y tocaba también a los profesores. De cómo les controlaban el horario, las llegadas tarde, la parsimonia en demasía para volver de los recreos. Debe haber salido entonces ahí el nombre de esa otra profesora, también de una asignatura humanística, que, como era además policía de carrera, cumplía de tanto en tanto algunas tareas administrativas. "Esa - deslizó Alejandra- es la peor. Me vive persiguiendo y controlando, haciéndose falsamente la simpática: '¿ya llegó, profesora?', ‘¿cómo está, profesora?'. 'Se me aparece para controlarme a cada vuelta de esquina!'. El comentario podría haber quedado ahí, pero siguió. Y Alejandra lo remató con una observación sobre la vida íntima y laboral de esa profesora-policía que, se apresuró a validar, ella conocía por los amigos que tenía en el Ministerio. La observación que me hizo rozaba el escándalo.

Pasadas las horas y el estupor, en el colectivo de regreso a casa, dejé constancia de esa información en mi libreta. Eso que Alejandra me había dicho me resultaba, en ese momento, tan privado y tan comprometido que supe que no iba a ser fácil poder

2 Algunas precisiones: la Escuela de Policía era, al momento del trabajo de campo, la única fuente de reclutamiento del personal masculino y femenino del cuadro de oficiales de la PPBA, mientras que la Escuela de Suboficiales y Agentes cumplía la misma función para el cuadro de suboficiales de la PFA. Vale explicar que la PPBA, como su nombre indica, cumple funciones de seguridad pública en el territorio de la provincia de Buenos Aires, la más grande y densamente poblada de la Argentina. Es, por esto, la mayor fuerza policial del país. La PFA ejerce su función a través de delegaciones a lo largo del país y, conjuntamente con la Policía Metropolitana, en la Ciudad Autónoma de Buenos Aires, capital de la Argentina. La investigación que guió el trabajo de campo en estas instituciones derivó en una tesis de licenciatura, una tesis doctoral y numerosos textos académicos sobre el proceso de construcción del sujeto policial en las escuelas de ingreso a la institución: las prácticas y discursos sobre el cuerpo y la corporalidad que buscan guiar el pasaje de lo civil a lo policial. Para mayores detalles de la investigación realizada, ver Sirimarco (2009)..

3 En una institución estatal y burocrático-penal como la policial, los primeros tiempos en el campo suelen estar signados, en partes iguales, por la curiosidad y la sospecha. Para una reflexión sobre este recelo y su viraje a lo largo del trabajo de campo, ver Daich y Sirimarco (2009), Simirarco (2012).

$4 \quad$ En el ámbito policial, el tratamiento de "doctora" implica una deferencia. En este caso en particular, también una gracia. 
utilizarlo. Estaba acostumbrada a las habladurías y cotilleos que cruzan el día a día del trabajo etnográfico. Pero eso era otra cosa. Eso era algo que nunca hasta entonces había escuchado y que nunca nadie me iba a volver a mencionar. Algo que solo Alejandra parecía saber, o que sólo Alejandra estaba dispuesta a señalar.

No me extrañó que Alejandra me lo contara. Tampoco que lo supiera. Sus relaciones ministeriales y sus dotes de observación propiciaban esto último. Para lo primero había otras explicaciones plausibles: desde el encono hacia la profesora que la controlaba hasta el lucimiento por la información privilegiada, pasando, por qué no, por la confianza que parecía tenerme. Después de todo, la ligazón entre secreto y rapport no es fortuita: ya Gluckman (1963) señaló, hace tiempo, que una parte muy importante de ganar la membresía a cualquier grupo es aprender sus escándalos: aprender que hay cosas que pueden decirse con aparente inocencia y cosas que solo podrían decirse con alusiones tan indirectas como descorteses.

Y otras cosas, añadiría yo, que no pueden decirse para nada. Al menos no por el antropólogo, al menos no sobre el papel. Eso sentí esa tarde, volviendo a casa, sobre lo que me había contado Alejandra. Refería a hechos que enlazaban de un modo complejo lo público y lo privado, y su divulgación en un artículo o una tesis —aun con todos los anonimatos y resguardos pertinentes - podía llegar a comprometer la imagen de una persona. Y a comprometerme a mí, al darle voz a un hecho que, por lo que sabía, no había forma aun de comprobar fehacientemente.

La conclusión me pareció obvia en el momento: lo que Alejandra me había contado era un chisme. Y más allá de los pruritos y los resguardos cuasi-legales, la preocupación de fondo era otra: ¿quién era yo para inscribir en un papel, con semejante ligereza, una semblanza que dañaba, gratuitamente, la vida de alguien? Resolví callarla. Después de todo, no era central para mi investigación y archivarla no resultaría costoso.

Hice todo el regreso a casa, sin embargo, con una frase de Geertz repicando en mi cabeza: "lo que principalmente hace el antropólogo es escribir" (en Reynoso, 1991: 30). Lo que Alejandra me había contado me perturbaba — recién ahí me di cuenta-, y lo hacía porque justamente impedía eso que Geertz declaraba, provocadoramente, como nuestro métier. Verdadero o no, había algo que ahora sabía y no podía decir. Y no podía decirlo - no podía escribirlo - porque era un chisme.

Pero, ¿qué tal si no lo era? Pasado el primer impulso, me asaltó otro. El de usar la información. Mejor dicho: no necesariamente el de usarla, sino el de considerarlo posible. Ese silencio que yo tenía valía varias palabras. Era como tener en la mano una pieza de rompecabezas que puede cambiar el dibujo del puzzle. Que esa información no fuera central para mi investigación no significaba que no iluminara lógicas institucionales. No significaba que no fuera un dato.

Pasó más de una década desde ese viaje de vuelta a casa. En todo ese tiempo no hice sino ir y venir entre uno y otro impulso, acumulando dudas e interrogantes que se ramificaban. ¿Qué hace el antropólogo cuando da con algo que no puede escribir? ¿Qué hace cuando se obtura el proceso de trocar lo dicho en dato? En un trabajo como el nuestro, acostumbrados como estamos a traficar con dichos y experiencias, ¿cuándo y por qué se alcanza el límite de lo decible?

Nunca, en todo ese tiempo, escribí ni publiqué nada que siquiera trasluciera esa información que me habían dado. Pero como es obvio, nunca tampoco olvidé el episodio. Supongo que porque fue de esos raros eventos que te fuerzan a hacerte preguntas que jamás te hubieras planteado de otro modo. 
Por eso, y por el tiempo transcurrido, en este trabajo quisiera rescatar ese suceso. Lo hago todavía con reservas, sin estar del todo convencida de traicionar ese silencio, pero creyendo al mismo tiempo que ese caso constituye un insumo de gran valor para reflexionar en torno a la antropología y su relación con la producción de conocimiento. Un suceso como el referido, justamente por sus implicancias y complejidades, no solo nos interpela en nuestra ética profesional, sino en la práctica misma de la disciplina, desnudando las tensiones con que construimos lo que se dice y lo que se calla, y exponiendo las relaciones de poder implicadas entre lo que el etnógrafo sabe, lo que se le permite saber y lo que alcanza finalmente el texto de la etnografía (Van Vleet, 2004).

La exposición del caso a continuación adolece expresamente de precisiones. Las vaguedades en tiempos e instituciones, sumados a los obvios cambios de nombres y localidades ${ }^{5}$, buscan obstruir las posibilidades de hilar personas y contextos, resguardando identidades. El tiempo transcurrido ha ayudado también a este proceso, resolviendo las implicancias legales que el suceso escondía y que lo volvían, en su momento, tan delicado. Ciertos detalles han sido evitados o cambiados, para preservar aun más las privacidades. El núcleo central del relato, pese a todo, mantiene su sentido y sus características.

\section{El caso. El chisme}

Patricia Suárez era, como decía, docente de la escuela y comisario. Andaba por aulas y pasillos en su uniforme azul oscuro, el pelo tirantemente recogido en una cola de caballo. Dictaba una materia humanística - era licenciada universitaria- y manejaba, como nadie, el arte de ganarse a los alumnos a punta de comentarios picantes. Sus clases siempre incluían la carcajada. A veces era por acotaciones que nada tenían que ver con la profesión policial: "no me joda, los colores no son cálidos ni fríos, esas son boludeces para Utilisima".

La mayoría de las veces, sin embargo, era por piezas de ese humor particular que todos los policías compartían. En un espacio mayoritariamente masculino, la galantería era moneda corriente, así más no fuera como registro formal de cortesía hacia las pocas mujeres de las aulas (alumnas, profesoras o antropólogas). No era raro que Suárez reaccionara a esas muestras de fanfarronería con dosis iguales de humor e ironía: "como mujer, madre de familia, esposa desde años del mismo hombre, me asustó, puso en riesgo mi fidelidad". Todavía recuerdo la mañana en que, finalizada la cursada, Suárez saludaba a todos los alumnos con un beso, deseándoles buena suerte. A uno le dio dos, y éste lo hizo notar, entre presumido y afectado, ante sus compañeros. La respuesta de la comisario no se hizo esperar: "ilo que faltaba, me va a denunciar por acoso, el maricón!".

Chistes o no, sus apreciaciones siempre eran contundentes. Por el cariz de su materia, muchas veces las clases desembocaban en debates de actualidad profesional o en dilemas personales. Los comentarios de Suarez aparecían, incisivos, para

\footnotetext{
5 Nombres y localidades fueron inventados y no corresponden a la realidad. Si estos llegan a coincidir con situaciones reales, es mera coincidencia.

6 Utilísima satelital: un canal de cable dedicado a programas "para la mujer" (cocina, decoración, moda, belleza, manualidades).
} 
desnudar los tópicos recurrentes del quehacer policial. De entre ellos, el juego entre vida privada y discurso moral era uno de los recurrentes, se tratara o no del ámbito laboral: "siempre hay una doble moral con hombres y mujeres. Si el principal" es atorrante, se festeja. Ahora, si el principal es mujer, ya es otra cosa. [Impostando una voz masculina]: 'iqué atorranta! Ya me parecía a mí que tenía carita de puta!'”, "las peores lacras no se ven. Yo voy en una $4 x 4$ y todos saben que es robada, pero voy en el colectivo y me hice un aborto y nadie sabe nada”; "¿qué le importa al mayor Barreto ${ }^{8}$ mi vida privada? Importa si trasciende".

Los alumnos la apreciaban, pero el humor y el diálogo que establecía con ellos no engañaba a ninguno. Todos sabían perfectamente que la cordialidad y las chanzas no trastocaban para nada la distancia que implica la jerarquía y el ejercicio de la autoridad. Me acuerdo ahora de un grupo de chicos en particular, que le había puesto apodos a todo el mundo dentro de la escuela. "Giselle Rimolo" a una profesora de mediana edad, largo cabello platinado, excesivo maquillaje y ropa provocativa9 " "Laisa Roldán" a una oficial no muy femenina en su apariencia ${ }^{10}$. "La mudita" a mí, que solía permanecer bastante callada cuando observaba las clases. "¿Y Suárez?”, me animé a preguntarles un mediodía después de un asado. "Suárez es la comisario Suárez", zanjó uno, riendo pero terminante, evidenciando los límites de la chanza. Y otro remató, riendo también: "jodida, como toda mujer con jerarquía. Tiene cara de haber entrado al calabozo a dar palos. Con eso que siempre dice, de que 'esto [se toca la insignia en el uniforme que marca la jerarquía] no está acá porque lo cagó una paloma'...".

Ni los alumnos ni Alejandra estaban solos en estas apreciaciones. También el personal de la escuela tenía opiniones semejantes:

Recreo al lado de la fotocopiadora, charlando con Marta y Susana [dos policías que cumplían tareas administrativas].

Marta [refiriéndose a Suárez]: Nadie la soporta, a "la comisario". Es re-vigilante. Susana: El otro día yo creí que lo mataba, a un alumno. Lo ve pasar por el pasillo y lo para y le dice: "con camisa larga va corbata". "Sí, sí, la traje", le dice el chico. "La trajo pero no la tiene puesta", le contesta. [Y señalando a un alumno que en ese momento estaba sentado a lo lejos y al que se le veían unas medias que no concordaban con el uniforme]: ¡Imaginate si ve pasar a ese con medias con rombos! (Registro de campo)

En este contexto de severidad con que se juzgaba la actitud de Suárez, las habladurías sobre ella no sobrepasaban el fastidio por sus labores de control (exageradas por motu propio o solicitadas bajo cuerda por el director de la escuela). De ahí que la información que me diera Alejandra me tomara por sorpresa. Ya dije que nos habíamos quedado charlando después de hora. Estábamos en un patio interno, alejadas del movimiento de profesores y alumnos, cuando Alejandra, intentando explicar algo que ya no recuerdo, soltó la bomba: "lo que pasa es que Suárez es la amante de un

\footnotetext{
Se refiere a un grado de la escala jerárquica: oficial principal.

Comisario mayor Barreto, director de la escuela.

Personaje mediático (amén de falsa médica), Giselle Rimolo luce la fisonomía homogénea que deparan las sucesivas cirugías estéticas y el monocorde modelo de belleza que las subyace.

10 Tal era el nombre de un personaje travesti en una popular comedia televisiva argentina.
} 
tal Marcos Bazán o Bazano, no me acuerdo bien. El de la departamental de Palermo que está implicado en el caso del comisario de Navarro ${ }^{11}$. La tienen guardada en la escuela para protegerla".

El caso del comisario de Navarro me sonaba. Estaba acusado de adquisición irregular de bienes y cobro de coimas ${ }^{12}$. El jefe de la delegación de Palermo, Bazán o Bazano, estaba también investigado por vinculaciones con ese hecho. Acostumbrada como estaba a la alta corrupción de la policía argentina, la información pese a todo no dejó de asombrarme. No por sus características ni por su simple ocurrencia, sino más bien por el hecho de que sucediera en un espacio como el educativo, que yo creía - hasta entonces - por fuera de capacidades y oportunidades de ilícitos de ese orden.

¿Qué sabía yo de Suárez? Sabía lo que ella había mencionado, al pasar, en algunas de sus clases. Revisé mi libreta de campo: que su último destino había sido una comisaría en Palermo, que su marido era el jefe de la departamental, que estaba en la escuela porque en Palermo no le daban comisarías a las mujeres, que era una privilegiada porque era profesional y policía: "todos los profesores debieran ser psicólogos y comando ${ }^{13}$, sociólogos y comando, cualquier profesión y comando, para poder dar cuenta de la experiencia policial. Éste [la educación policial] es un terreno virgen, y en formación estamos necesitados del aporte de todos".

Incluso una vez le había preguntado por su traslado a la escuela, extrañada del hecho de que hubiera dejado su vida familiar en Palermo (esposo e hija) y destinos anteriores en comisarías, para dar clases. En mi libreta tenía anotada su respuesta:

Yo estaba de segunda en la departamental. Tendría que haber ascendido y pusieron a otro. Así que tenía dos opciones: conformarme y quedarme atendiendo el teléfono, o buscar otra cosa. Armé un curriculum y vine a los institutos. Me tomaron en Narcotráfico y me hicieron preparar los programas de Psicología Aplicada, Sociología, etc. Después de estar todo el verano trabajando, cambiaron al tipo que me había llevado y me quedé sin trabajo. En eso vine acá a hacer un trámite y conseguí una audiencia con Barreto. Justo había echado a un profesor, le gustó que fuera comando, le caí bien, y me quedé.

Su explicación de los hechos distaba bastante de la información que me había dado Alejandra. Una vez enterada del supuesto secreto, quise saber cuántas versiones más soportaba la historia. No me costó nada aprovechar una charla con el director de la escuela, para preguntarle, al resguardo de su despacho, por los profesores del lugar. Llevé la conversación hacia las designaciones y pasamos revista a todos los docentes de la casa. A los pocos minutos llegamos a Suárez:

Suárez trabajaba en la oficina de personal en Palermo, su jefe me llamó y me la propuso: "tengo una graduada por la Universidad". "Bueno, mandala, que traiga un programa".

11 Se trata de estructuras de comando. Las departamentales coordinan las tareas policiales dentro de una jurisdicción, englobando bajo su mando la coordinación de varias comisarías.

12 Coima: gratificación con que se soborna a un funcionario público, cohecho.

13 El personal policial se divide en los siguientes agrupamientos: comando, servicios y personal civil. El agrupamiento comando es el personal abocado a funciones de seguridad, prevención, represión y mantenimiento del orden público. 
Eso fue todo lo que supe entonces respecto de su llegada a la escuela. No volví a saber mucho más sobre el caso hasta pasados unos meses. Charlaba con Marcela - profesora y psicóloga - en un recreo, cuando de pronto me contó que Suárez le había pedido a ella, "porque le parecía una profesional confiable", que por favor viera al marido, que había quedado implicado "en un problema de plata". No recuerdo si Marcela sabía o no lo del caso de Navarro, o qué era lo que sabía o sospechaba, pero sí recuerdo lo que dijo a continuación: "lo vi dos veces, porque el tipo no vino más. Comisario mayor. Marcos algo. Era raro, hablaba de 'Patricia', y de 'Patricia y su hija', y de otra familia, como si esa no fuera la suya. Decía que él no habia hecho nada". Volví a recordar las palabras de Alejandra. Si lo que me había contado era verdad, parecía como si Suárez hubiese intentado hacer pasar al amante por marido para conseguirle ayuda terapéutica.

Después ya no supe nada más. No le dije nada a Marcela ni a nadie, guiada por ese primer impulso que me llevaba a considerar que lo que Alejandra me había contado entraba en la categoría de chisme. Es decir, en el terreno de ese runrún incomprobable y soltado ligera — tal vez hasta malévolamente - con que los seres humanos solemos hablar de los demás. Por una cuestión de delicadeza profesional - que no de falsa moralina - me parecía de mal gusto repetirlo ante otros o sobre el papel. Fundamentalmente por esas tres razones que acabo de sugerir: por su sospechoso carácter de verdad, por su probabilidad de discurso malintencionado y por su soterrada condena moral.

La información de Alejandra tenía, por ellas, todos los condimentos que los estudiosos le han adjudicado al chisme. Era un relato sobre el comportamiento ajeno y sobre una persona ausente. Era un comentario malintencionado y no corroborado de verdad. Era una observación que informaba sobre reputaciones, recelando prestigios. Era, sobre todo, la comunicación de una denuncia moral (Fonseca, 2000; Fasano, 2008; Fasano et al., 2009; Calandrón, 2014).

Que quede claro: no traigo a colación estos sucesos para confirmarlos en su verdad, de la que sé poco y nada. Los traigo en su carácter de chisme. Es decir, en su carácter de elementos de una dinámica donde prima lo dicho antes que su comprobación. Porque poco importaba, en ese caso, que lo que contaba Alejandra fuera o no verdadero. Importaba en cambio que el mensaje circulara: no el hecho verificable sino su posibilidad. Y más que el hecho posible, la expresión pública de su condena.

Es que el chisme - como varios autores clásicos ya han señalado - no es sino un género conversacional, un juego culturalmente controlado, con importantes funciones sociales. El chisme, el escándalo, el secreto ${ }^{14}$, operan como una práctica comunicativa del decir y el silenciar, como un evento performático del habla con particulares criterios nativos (Gluckman, 1963; Abrahams, 1970; Abrahams y Bauman, 1971; Epstein, 1969; Lowry, 1980; Tefft, 1980).

Lo que Alejandra me había contado podía ser entendido como un mero chisme y ser reprobado en consecuencia. Pero era justamente ese cariz el que lo volvía socialmente sugerente. Algo había, en el chisme sobre Suárez, que hacía que no me lo pudiera sacar de la cabeza. Y no era el morbo por el escándalo ni la ofensa por una supuesta moral quebrantada. Era más bien todo lo que el chisme decía: el espacio borroso de fuerza social que corría por debajo de la habladuría.

14 Dichas categorías no son necesariamente lo mismo. A los efectos del caso analizado, sin embargo, las mencionaré como pertenecientes a un mismo conjunto discursivo. 
$\mathrm{Y}$ es que, en tanto herramienta positiva para la reproducción de los discursos ${ }^{15}$, el chisme entraña potencialidades. Podríamos decir que habilita, en principio, una zona de decibilidad: un espacio donde se garantiza la posibilidad de hacer afirmaciones que no pueden discutirse de manera directa. El chisme dice de una persona lo que jamás podría decirse frente a ella, y en eso reposa parte de su valía, pues permite proferir evaluaciones morales de los otros sin entrar en enfrentamientos directos (Gluckman, 1963; Fasano et al., 2009). Permite — para volver a nuestro ejemploque un tópico espinoso como el proceder de Suárez tenga, a pesar de su voltaje, forma de ser dicho.

Y éste es otro de sus puntos centrales. Si el chusmear tiene la capacidad de tensionar el tejido social al ventilar cuestiones públicas y privadas, es solo porque se alimenta primordialmente de conductas en discusión. Esto es, de conductas cuyo valor moral permiten la disputa y el juicio (Fasano et al., 2009). Es que el chisme habilita, en segundo lugar, un espacio de ejercicio para la censura moral. Puede verse claramente en nuestro ejemplo, donde esa condena sobrevuela, tácita pero clara, cada palabra proferida por Alejandra: de seguro el engaño al marido ${ }^{16}$, pero sobre todo los negocios ilegales. O la aparente contradicción, también puede ser, entre la vida de Suárez y su discurso público tan reprobatorio de la moral de los otros.

En todo caso, en esto radica también parte de su potencia: si el secreto actúa intentando demarcar una división entre lo público y lo privado (entre lo que se puede decir abiertamente y aquello que por íntimo no debería interesar a nadie), su comunicación interpela la flagrante falsedad de esta separación, devolviéndolo de lleno a la esfera de lo público (Manderson et al., 2015). No otra cosa me dice Alejandra, al contarme el chisme: que en el ámbito de esa escuela policial en que nos movemos, la información que ella tiene nos importa a todos. No necesariamente porque involucra a Suárez (aunque también), sino porque desnuda patrones de conducta sobre modos de relacionamiento, oficios e irregularidades.

Pues el chisme habilita, en tercer lugar y sobre todo, un espacio de verosimilitud. Lo decíamos anteriormente: su propagación no implica condiciones de certeza, sino de plausibilidad (Fasano et al., 2009). Lo que importa en ellos no es la constatación meticulosa de los hechos que refiere - si tiene razón Alejandra, Marcela o mi libreta, si el jefe de la departamental de Palermo es el marido o el amante de Suarez-, sino que esos hechos sean probables. Es decir: que sea probable que Suárez tenga un amante, que sea probable que esté ligada a la comisión de un delito, que sea probable que una escuela sea un espacio apto para el ocultamiento.

Porque el chisme es, finalmente, una forma de conocimiento cultural que borronea los límites entre los eventos sucedidos y los eventos imaginados. No es tanto una fuente de lo que ha sucedido, sino de lo que puede haber pasado (Stoler, 1992). Se sobreentiende: de lo que puede haber pasado en un contexto determinado, bajo la órbita de lógicas particulares. Los chismes expresan lo posible. Y es justamente eso lo que los vuelve socialmente significantes.

15 No pretendo extenderme aquí en un análisis pormenorizado sobre el chisme, sino rescatar algunos lineamientos que se vinculan directamente con el caso analizado. Para una reflexión exhaustiva acerca de este género conversacional, ver los autores señalados.

16 Aunque no es claramente el caso, es importante notar el papel primordial del chisme como forma de control de la sexualidad de las mujeres. A este respecto, ver Lees 1989. 


\section{El caso. El dato}

Ya dije que, al primer impulso del silencio, le siguió otro, de signo contrario. Porque lo que Alejandra me había contado se deslizaba hacia lo personal y lo íntimo, pero también revelaba patrones institucionales.

Uno, evidente hasta el hartazgo, acerca del espeso entramado de ilícitos, delitos y corrupciones que atraviesa a las policías argentinas. No voy a aburrir al lector con un detalle pormenorizado de estas situaciones, que son ya de dominio público. Nadie, a nivel nacional y regional, desconoce la faceta represiva y criminal en que se ha visto envuelta la mayoría de las policías de la región. En nuestro país, los casos generalizados de violencia, brutalidad y corrupción policial — represión de la protesta social, persecución de sectores vulnerables, muerte de detenidos en comisarías, episodios de "gatillo fácil", comisión de ilegalismos, vínculos con el crimen organizado- ha transformado a estas instituciones en una fuerza bajo sospecha constante.

Las razones son complejas y superan el espacio disponible, pero baste señalar que, si bien se trata de cuerpos civiles de seguridad, la normativa y la práctica los han estructurado con esquemas de autoridad militar, jerarquías rígidas y sistemas de control interno corporativos y poco transparentes. Sumado a esto, el particular desarrollo histórico-institucional las ha orientado a la represión de las actividades políticas disidentes y del pequeño delito, consolidando una tradición donde el uso de la fuerza es concebido como un ejercicio discrecional y arbitrario que no admite el control externo (Tiscornia, 1998, 2008; Martínez y Eilbaum, 1999; Sain, 2008; Frederic, 2008; Pita, 2010).

En este contexto donde la equiparación corrupción y policía se ha naturalizado, enterarme del caso de Navarro no me sorprendió en lo absoluto. Ni su existencia ni la supuesta vinculación de Suárez con él. Recuerdo haber buscado en los diarios algún dato confirmatorio. Allí figuraban, en las páginas de La Nación, Página/12 y La Prensa, los nombres de Marcos Bazán y del comisario de Navarro, asociados a una investigación por enriquecimiento ilícito. El patrimonio de este último se había incrementado de modo llamativo y la indagación del caso había llevado, tras pistas y allanamientos, al nombre de Bazán. Ambos policías habían trabajado juntos en un destino anterior: Bazán como jefe de delegación, el comisario de Navarro como su secretario. Esa delegación, no casualmente, era una de las más poderosas y ricas de la zona; en ella se urdían, según la prensa, negocios fuertes-prostitución, tráfico de drogas, desarmaderos ${ }^{17}$.

Los diarios se regodeaban en la comunicación de estos y otros detalles. Ni una alusión, sin embargo, se filtraba sobre el nombre de Suárez. O no tenía nada que ver, o era demasiado pronto en la investigación, o la red de protección estaba funcionando. Estuviera o no vinculada con él, el caso estaba bien documentado. Lo que aparecía en la prensa era concordante con lo que Alejandra me había contado.

Y lo que me había contado no sólo desnudaba un hecho puntual de corrupción, sino, asimismo, un segundo patrón institucional, también bastante transitado. El "amantazgo", según sus palabras. O, para salir de categorías de tiente moralista y sistemas fijos de sexualidad, las relaciones sexuales en el ámbito laboral ${ }^{18}$. Práctica

17 Desarmaderos: negocios de comercialización ilegal de repuestos de autos, relacionados con el robo de vehículos.

18 El uso subsiguiente de este término intenta respetar la categoría nativa, sin necesariamente acordar en la idea de amor y sexualidad monógama que sostiene. 
esta que, a juzgar por las referencias nativas, se considera una constante dentro del mundo policial. "El policía es muy mujeriego porque están rotos los lazos con su familia - me explicaba una vez un joven oficial- Trabaja todo el día afuera, hace turnos de varios días, a la mujer y los hijos casi no los ve. Entonces, cinco minutos con una amante, sí se puede. A tu mujer no te la podés coger ${ }^{19}$, tenés que amarla". Otro suboficial, más curtido, lo explicaba de otro modo: "es que el vigilante ${ }^{20}$ es cararrota ${ }^{21}$ como yo, cara de piedra. Total el "no" ya lo tengo seguro. Aparte, como decimos los vigilantes, de veinte [mujeres] que te chamuyás ${ }^{22}$ en la calle, una te va a dar cabida ${ }^{23}$. Todos los vigilantes tenemos dos o tres mujeres".

No pocas veces, a lo largo de mi trabajo de campo por distintas dependencias, pude comprobar la veracidad de estas máximas (que obviamente alcanzan también a las mujeres policías). No era algo que se publicara a los cuatro vientos, por supuesto. Pero bastaba con observar atentamente $y$, más temprano que tarde, pequeños gestos de intimidad entre jefes y secretarias, por poner solo un ejemplo, dejaban traslucir relaciones que imbricaban lo laboral con lo sexual.

(Estoy generalizando, desde ya, pero la generalización solo intenta reflejar un estado desnudado como mayoritario desde el mismo campo. No por nada un viejo chiste que circula al interior de la fuerza se ufana de que es del policía el único velorio con dos viudas) ${ }^{24}$.

En este estado de situación, lo que Alejandra me había contado también resultaba plausible. Que Suárez fuera la amante de Bazán era algo que podía tener visos de verdad, y que se revelaba por ello como socialmente significante. No por el hecho trivial del amantazgo — moneda corriente en cualquier ámbito — sino por las características puntuales que adquiere en un espacio como el policial. Lo que las palabras de Alejandra dejaban entrever era que lo importante no era el simple hecho de tener un amante, sino quién era el amante de quién.

Suárez, según parecía, era la amante del jefe de una Departamental. Y de una Departamental en concreto, asociada al manejo de grandes sumas de dinero. De hecho, la vinculación de Bazán con el comisario de Navarro había saltado a la luz a raíz de la existencia de una caja de seguridad bancaria con una obscena cantidad de dólares en su interior. Suárez, de serlo, no era la amante de un policía cualquiera.

Y eso, justamente, desnudaba estructuras de relacionamiento: unas donde la sexualidad adquiría un rol preponderante. Un suboficial de varios años en la fuerza me lo explicaba de este modo:

Las vigilantas son putas con chapa. La vigilanta no se va a acostar conmigo. ¿Sabés lo que pasa? Nosotros los vigilantes con las vigilantas somos el agua y el aceite. Nunca me acosté con una vigilanta, ¿sabés por qué? Porque no te puedo mentir,

19 Coger: forma coloquial de referirse al ejercicio del acto sexual.

20 Por fuera del ámbito policial, el término "vigilante" designa, por extensión, a la totalidad del personal policial. Al interior de la fuerza, hace referencia al policía del cuadro de suboficiales. Es decir, al personal subalterno.

21 Cararrota: atrevido.

22 Chamuyar: hablar mintiendo o exagerando. En este caso, para conquistar a una mujer.

23 Dar cabida: aceptar.

24 El tópico del "policía mujeriego" es, por supuesto, una construcción discursiva. Que muchos policías gusten de presentarse de ese modo no implica necesariamente que lo sean. Lo interesante, en todo caso, es la vinculación que esos discursos profesionales tejen entre lo policial y cierto ejercicio de la masculinidad. Para una reflexión en torno a este eje, ver Sirimarco (2009) y Daich y Sirimarco (2014). 
porque vos sabés todas las mentiras que te puedo llegar a echar. ¿Qué te voy a decir? ¿Que me tuve que quedar encerrado [en la comisaría] porque hubo razzia? Si vos sabés que no hay más razzia. La vigilanta se va a acostar con un jefe, se va a acostar con el comisario para estar bien, para que le ponga las horas extras, para ganarse un franco, para no venir un domingo a laburar, para irse a la hora que se quiera ir. No todas, pero un $99 \%$.

La opinión puede ser extrema, pero la imagen que brinda es clara: la sexualidad en el espacio policial — como señala Calandrón (2014) - es un insumo estratégico para la regulación de las relaciones profesionales. Pues tener sexo dentro de las dependencias policiales no solo es bien visto: es hasta una habilidad necesaria para manejarse en el trabajo ${ }^{25}$. El ejercicio de la sexualidad, así practicado, no hace sino construir relaciones de poder desde donde obtener prebendas - sean estas la obtención de espacios de trabajo especiales, la asignación de tareas más sosegadas o la exención de cargas laborales obligatorias.

El uso político de la sexualidad no es ninguna novedad a descubrir, ni por fuera ni por dentro del ámbito de trabajo. En el contexto que analizamos, sin embargo, se traduce en prácticas particulares que nos hablan de los modos de sociabilidad del mundo policial. Que el ejercicio de la sexualidad excede el terreno de lo privado queda suficientemente probado: antes que una práctica circunscripta dentro de los límites de lo personal, se trata de una herramienta apta para la negociación en el terreno de lo público. Es decir, siguiendo las palabras de Calandrón (2014), de una habilidad profesional.

Lo que nos permite avanzar hacia el siguiente y obvio corolario: la importancia de las relaciones personales en la dinámica de funcionamiento del universo policial. $\mathrm{O}$, lo que es lo mismo, la compleja combinación de lo público y lo privado que regula el ejercicio de la actuación profesional. Porque como sostienen varios autores para campos semejantes —el judicial, el político-, estos ámbitos funcionan regidos por dos lógicas imbricadas. Una, la de las leyes y las normativas. Otra, la de las relaciones personales (familia, parientes, amantes, amigos, compañeros). Así, el funcionamiento de estos ámbitos solo puede ser comprendido en la interrelación de estas dos esferas; esto es, en la relación de reflexividad que establecen la una con la otra. Porque las relaciones personales no constituyen una falencia o una deformación del sistema, sino uno de sus factores estructurales. Y sin la comprensión de estos mecanismos, el entendimiento de los modos de conformación de estructuras, espacios y relaciones institucionales queda incompleto (Neiburg, 2003; Sarrabayrouse Oliveira y Villalta, 2004).

En lo que al ámbito policial refiere, la trayectoria profesional no podría explicarse solo por la apelación a normativas, ascensos reglamentados y pases formales de destino. Sin la malla de relaciones personales que vincula a los individuos dentro del sistema, ¿qué conexiones podrían establecerse, a priori, entre un jefe de la Departamental de Palermo, un comisario de Navarro y una docente de una escuela policial a $500 \mathrm{~km}$ de distancia de cada uno? Solo un buen entendimiento de la configuración de las tramas policiales permite recuperar la huella de los relacionamientos —anti-

25 Desde ya, no siempre y no en relación a todo el mundo. Para una complejización de los límites del ejercicio de la sexualidad y sus moralidades asociadas, ver un estudio de caso en la PPBA en Calandrón (2014). 
guos colegas, amigos, amantes - que explican el cómo y el por qué del entramado presente. La red de sociabilidad es fuerte y tiene raíces hondas.

Tan fuertes y tan hondas como sus lealtades, que llevan a que una policía presuntamente implicada en un caso de corrupción termine protegida dentro de una escuela de policía. Constatación que nos conduce al tercer patrón institucional que las palabras de Alejandra iluminan: la configuración de un mapeo institucional con destinos diferenciales y, sumado a esto, la existencia de un complejo sistema de premios y castigos para acercarse o alejarse de esos destinos.

Que una escuela de policía pueda servir de espacio para el ocultamiento está íntimamente vinculado con esta realidad. Los institutos de formación — tal la denominación institucional - son, dentro del ámbito policial, un espacio mayormente desestimado $^{26}$. En primer lugar, porque la noción de educación misma lo está. En el instituto destinado a los cursos obligatorios para el ascenso de los oficiales de la PPBA, era frecuente encontrarse con policías que habían sido suspendidos, apartados de sus labores específicas o castigados de otros modos sutiles por sus jefes en su lugar de destino por "abandonar" sus puestos de trabajo durante las semanas que duraba el curso de reentrenamiento que - repito - era obligatorio. En el contexto del trabajo policial en comisarías — plagado de exigencias, urgencias y recargas horarias - la afectación de policías a labores educativas era vista no solo como una pérdida de personal, sino de tiempo.

La explicación de semejante valoración tal vez repose, en última instancia, en una afirmación que no pocas veces escuché en el campo: "yo entré acá para no tener que estudiar. Si hubiera podido seguir estudiando en la Universidad, ¿te pensás que estaría en Policía?". Las afirmaciones parecen contrapuestas - entrar a la policía como a un trabajo ante la renuencia a estudiar, entrar a trabajar porque no se tienen medios para seguir estudiando_- pero apuntan a un mismo sentido: el de la concepción de lo policial como un ámbito laboral en riña con la potencialidad de seguir perfeccionándose teóricamente.

Ahora bien, la desestimación de lo educativo explica solo en una pequeña parte la impugnación de las escuelas policiales como un destino laboral atrayente. Una razón más importante, si no la principal, es su nula vinculación con la capacidad de administrar ilegalismos (y su consiguiente reporte de dinero). Una escuela no es una comisaría, mucho menos una Departamental. Las posibilidades económicas que se derivan de las labores bajo cuerda que allí se llevan a cabo vuelven a los institutos de formación un destino escasamente atractivo. Las posibilidades de una comisaría son múltiples: desde el cobro modesto de permisos para el ejercicio de un oficio (prostitutas, travestis, vendedores ambulantes) hasta el cobro de sumas importantes por hacer la vista gorda ante negocios turbios (juego clandestino, boliches sin habilitación, ferias ilegales). Nada de esto es posible en una escuela policial.

Por ello es común que la escuela sea, como tantos otros destinos, uno de los modos institucionales del afuera, donde son re-ubicados aquellos que no han logrado insertarse en el legítimo ejercicio de la función - ya sea esto tener poca pasta para el oficio o no avenirse a formar parte de sus "negocios". Para estos seres que han sido marginados, el "castigo" adquiere la forma de traslado a un destino perdido o una función desprestigiada, donde nunca pasa nada (y lo que nunca pasa es la plata).

26 Esta afirmación no abarca, desde ya, a la modesta proporción del personal policial realmente interesado y abocado a cuestiones docentes y educativas, que han hecho de esta temática el eje de su carrera profesional. 
Y es justamente porque allí no pasa nada que la escuela se vuelve, también, un terreno propicio para la invisibilidad positiva. Un ámbito de protección y no solo de castigo. Un espacio donde Suárez puede ser enviada para ser sustraída de las miradas. Un lugar donde permanecer a la espera de que se calmen las aguas.

Eso, decía Alejandra, es lo que había pasado con Suárez. Nunca, en lo que llevaba de trabajo de campo, me había encontrado con algo parecido. Por todo lo que acabo de argumentar, siempre había concebido a las escuelas como espacios no salpicados por la corrupción policial. La escena que me descubría Alejandra empezaba a hacer tambalear mis precarias ideas. ¿Cuánta ropa sucia, en realidad, se lavaba en lugares como esos?

Las palabras de Alejandra precipitaron ésta y otras preguntas, que me forzaron, andando el tiempo, a escuchas más atentas en el campo y, con ellas, a la ampliación de la mirada. Porque esas palabras, sin dejar de poner sobre el tapete la vida privada de Suárez, expusieron también allí dinámicas institucionales que empezaba en parte a descubrir, en parte a confirmar. La corrupción, los lazos personales, el ejercicio de la sexualidad, los sistemas de lealtades y protecciones, los espacios de ocultamiento y desprestigio: los puntos de reflexión que abrió el chisme de Alejandra lo reconvirtieron en información valiosa para la comprensión de lógicas profesionales ${ }^{27}$.

Porque no otra cosa fueron, para mí, sus palabras. Con ellas se abrieron capas sucesivas de comprensión, con profundizaciones más o menos disponibles según la escucha. Antes de que Alejandra me contara lo que sabía, Suárez solo era para mí una policía de carrera cuyos avatares profesionales (me refiero a la injusticia de no haberle sido otorgada la dirección de una comisaría por el hecho de ser mujer ${ }^{28}$ la habían llevado a tomar un trabajo lejos de su familia. Una vez enterada de los comentarios que corrían, la escena entera se reconvirtió. Otras personas podrían haber traducido esos comentarios en una información banal y personalista: la existencia de una policía corrupta que trabajaba en una escuela y tenía un esposo y un amante. Para mí se convirtieron, esos comentarios, en el ojo de cerradura desde el cual atisbar lógicas institucionales. Y por eso se transformaron en dato.

\section{El chisme. El dato. La etnografía}

Pasó, como dije, el tiempo. Cada tanto, la prensa seguía trayendo novedades del caso. Los dos policías implicados pasaron a disponibilidad preventiva y fueron apartados de sus funciones. El nombre de Patricia Suárez salió en un momento a la luz: su número de teléfono aparecía junto a anotaciones por altas sumas de dinero en la

27 Se comprenderá entonces que el tratamiento que he hecho de estas dinámicas no sea exhaustivo. El objetivo de este trabajo no pasa por desmenuzarlas teóricamente, sino por desplegarlas en conjunto para ilustrar con ellas el valor de dato que se encuentra enmascarado en eso que, a priori, puede tomarse como chisme.

28 Esto, por supuesto, también es un dato. La explicación de Suarez, sea verdadera o falsa como causante de su llegada a la escuela, habla también de patrones institucionales (el lugar diferencial que hombres y mujeres ocupan en la institución policial, el poder policial y el mando como cuestiones ligadas a lo masculino, etc.). Si he elegido no desplegar aquí estos entendimientos es porque he optado por centrarme en la información relevante que se comprime en aquello que vemos en primera instancia como chisme. En todo caso, es interesante comprobar que el dato es una cualidad inherente a las interpretaciones del mundo, y no a la verdad o falsedad de sus enunciados. Para un acercamiento a las cuestiones de género en la agencia policial, ver Sirimarco (2009) y Calandrón (2014). 
agenda del jefe de la Departamental y su domicilio en Palermo fue allanado. Después, tan súbitamente como había aparecido, el nombre desapareció. La justicia la desestimaba como sospechosa.

El asunto siguió su curso. Juicio oral, fallo condenatorio, apelaciones, Corte Suprema de la Nación y, finalmente, al cabo de un lustro, sentencia firme. Una condena de varios años de detención por enriquecimiento ilícito para cada uno de los policías, más inhabilitación de funciones y multas. Junto con estas condenas aparecieron otras, y con ellas los nombres de otros implicados, testaferros todos del comisario de Navarro. Ninguno de ellos era el nombre de Suárez. Ni avanzada la causa ni después su nombre volvió a mencionarse.

Con el caso resuelto y el tiempo transcurrido, volví a pensar en Alejandra, en Suárez, en lo que había sabido y había callado, en todo lo que decía eso que no había dicho. Lo que la primera había contado sobre la segunda se revelaba de algún modo verdadero (me refiero a su vinculación con el caso del comisario de Navarro). La justicia había terminado desestimando su participación en el hecho, pero su casa había sido allanada durante las investigaciones de la causa. Lo que me había contado Alejandra lo corroboraba la prensa: Suárez había estado implicada en los primeros movimientos del caso. El comentario que la profesora me había hecho empezó entonces a parecerme, más que un chisme, una verdad a sotto voce ${ }^{29}$.

Y eso inauguró las primeras reflexiones, que acá recreo. Es sabido que la cuestión de la ética y el compromiso es un desvelo que asalta repetidamente al antropólogo. Oído e intercambiado a placer en el terreno, las dudas sobre el cotilleo irrumpen cuando nos enfrentamos al texto escrito. Porque si, como dice Gluckman, el acceder al conocimiento del otro nos hace parte, nos hace parte para conocer tanto como para callar. No importa que el chisme nos lo hayan dicho expresamente en nuestro carácter de antropólogos - Alejandra me dice lo que me dice para que yo sepa, para que yo entienda-, sabemos sin embargo que revelarlo públicamente puede destruir el campo que construimos. Porque el chisme es, como cualquier dato sensible, una pieza política, cruzada por posicionamientos y relaciones sociales que nada tienen de inocentes.

Pero no es la reflexión por su contexto de uso lo que me inquietaba, sino una pregunta si se quiere anterior. Aquella que focaliza en el proceso de conversión del dato sensible en chisme. $\mathrm{O}$, lo que es lo mismo, en el proceso de privación de dato que estos chismes encarnan. Aunque las reflexiones que siguen se ciñan exclusivamente a las particularidades del caso que analizo, confío en que puedan servir para alumbrar reflexiones un poco más generales acerca de la naturaleza del chisme, la naturaleza del dato y la naturaleza del oficio antropológico.

La relación entre chisme y dato lleva aparejada la pregunta más básica por la construcción de este último. Me había interesado por esta cuestión algún tiempo atrás, de algún modo si se quiere tangencial. En una compilación sobre el cómo de los estudios policiales, me había intrigado develar qué hace específicamente el investigador cuando está en el campo, en un intento por visibilizar el proceso de producción mismo del conocimiento ${ }^{30}$.

29 Si bien es cierto que el proceso judicial se pronunció sobre un caso de corrupción, también es cierto que nada fue dirimido respecto a la afirmación de "adulterio" contenida en el chisme. Si me he atrevido a avanzar sobre esto es porque ninguna pieza de la información aquí desplegada puede —en virtud de los cambios, omisiones y añadidos sufridos - servir para reconocer a Suárez, ni siquiera en las instituciones donde desarrollé el trabajo de campo.

30 Para mayores datos sobre esta reflexión, ver Sirimarco (2010). 
Ya Van Maanen había abogado, muchos años antes, por descripciones más detalladas de esas actividades en el terreno, en un llamamiento a romper con la idea de que "la 'recolección de datos' en sí es algo así como una actividad automática, monótona, un aspecto de la investigación poco merecedor de análisis detallado", que hace que se crea, erróneamente, que "una vez que los puntos a tratarse son seleccionados, que los niveles y objetivos de la investigación son decididos y se establecen los arreglos de procedimiento para el acceso, la información llegará de un modo mecánico y sin problemas" (Van Maanen, 1978: 346).

Sabemos ampliamente que esto no es así. Que los métodos usados para desarrollar la investigación no guardan nada de automáticos, que la información que se obtiene no es una consecuencia lineal de la utilización de dichos métodos y que, en definitiva, el dato que el investigador busca no se recoge, sino que se produce. Ya sea en un trabajo etnográfico o en un trabajo de archivo, el "dato" no es una manzana que espera a priori en el "campo" a que el investigador llegue para tomarla. El dato es el producto de la interacción de varios factores, cientista social incluido (Sirimarco, 2010, 2012).

La pregunta obligada era simple: ¿cómo, el investigador, produce la información requerida? El episodio con Suárez reflotó esa pregunta que me había hecho tiempo atrás y desnudó sus complejidades. Atendiendo a que el campo no es una instancia mansa a la espera de la observación del etnógrafo, sino el resultado de encuentros y confrontaciones, y a que todo dato es, por ende, una construcción en conjunto - muchas veces en disputa-, los interrogantes se amplificaron: ¿cómo, la competencia y el saber profesional de cada cual, delimita las zonas de aquello que se conserva o se desecha? ¿Qué constituye un dato para cada quién?

A medida que le daba vueltas a esas nuevas preguntas, la separación entre chisme y dato, en el caso que manejaba, empezó a desdibujarse. Como si, de tanto insistir en la reflexión, la carga descalificatoria del primer término se diera de bruces contra la práctica antropológica. ¿Cuál era, en última instancia, el prurito que me había llevado a desestimar como chusmerío algo que evidentemente podía ser mucho más?

Se me dirá que chisme y dato no son, necesariamente, instancias contrapuestas. Que algo puede ser particularmente relevante para la investigación y aun así ser catalogado de habladuría. El porqué de esta catalogación es lo que me desvela. Si lo que callamos en el texto etnográfico está tan culturalmente construido como la información que presentamos, ¿qué distinción semántica opera separando las aguas entre una y otra variable? ¿En base a qué parámetros construimos lo indecible? O para volver a la pregunta del párrafo anterior: ¿cuál es el prurito epistemológico sobre el que edificamos vacíos de narrabilidad?

Pensé, en primer lugar, en el valor de lo íntimo. Algo queda descalificado como dato - me dije - cuando entraña cuestiones que rozan el ámbito de lo personal. Pero la teoría antropológica nos ha demostrado largamente que "público" y "privado" no son esferas antagónicas ni discernibles en la praxis, sino - como acabamos de vervariables que se imbrican y se retro-alimentan. Lo que indicaría que el chisme, lejos de ser una cuestión que involucra únicamente la intimidad inviolable de las personas, puede ser fácilmente conceptualizado como un acto social a través del cual la gente significa relaciones y eventos, ordenando de modo coherente experiencias cotidianas (Ochs y Capps, en Van Vleet, 2004).

Pensé luego en el valor de lo falso: lo que oímos se descarta cuando implica un nivel no comprobable de verdad. Pero esto no podría ser menos cierto. La etnografía 
ha trabajado, desde siempre, con discursos sociales y, por ende, por fuera de cualquier entendimiento de una verdad esencialista y de una categorización moral de lo verdadero y lo mentiroso. Un discurso es, por definición, una pieza no necesariamente gobernada por la verificación empírica, sino por la necesidad comunicativa. Lo que equivale a decir que no representa sino que construye realidad; es decir, que lo que importa no es cuánto se acerque o se aleje de ella, sino la clase de realidad que ayuda a conformar (Carr, 1986; Bruner, 1991, 1998; Ochs y Capps, 1996; Sirimarco, 2015). Lo importante del discurso no es su veracidad, sino su actuación, y ello vuelve al chisme - a pesar de su falta de verdad o a causa de ella - un tipo particular de narrativa (capaz, como toda narrativa, de ser aprehendida socialmente).

Pensé finalmente en un tercer prurito: aquel que relaciona el chisme con su contexto de producción. Una pieza informativa se desecha cuando sobrepasa lo que alguien accede a decir en primera persona ante el antropólogo. Es decir, cuando implica un comentario que nadie haría de sí voluntariamente. Pero esta presunción también es falsa, y entraña una pretensión epistémica bastante en riña con el oficio antropológico. Es usual que el método etnográfico se solace en la enfatización de técnicas como la inmersión en el terreno, la observación-participante y la entrevista abierta y en profundidad, pero ¿cuán oscurecido queda el hecho de que el conocimiento que producimos en el campo es en realidad deudor de una multiplicidad de eventos comunicacionales, no siempre tan pautados ni tan en control de las personas en el terreno ${ }^{31}$.

Es que las etnografías tienden a desatender, muchas veces, la descripción de las condiciones en que se construyen los datos, como si estos realmente se nos brindaran lineal e inocentemente. Trabajamos con discursos sociales. Es decir, con un tejido apretado y fragmentario de cosas dichas, oídas, sugeridas o calladas, de cosas que se dicen sobre uno mismo y cosas que se dicen sobre los demás, de cosas que se expresan cara a cara y cosas que se escuchan al paso. Trabajamos con lo que dice la gente y también con lo que no: cruzamos información, sondeamos, comparamos puntos de vista, re-preguntamos. En síntesis: construimos nuestro conocimiento a partir de datos cuyas situaciones de producción son tan múltiples como diversas.

Esto, por supuesto, no es ninguna novedad. Lo que hacemos cotidianamente en el campo es algo que ya Simmel describía muy bien a comienzos del siglo XX. El conocimiento que producimos — sostenía_ "se basa en nuestra habilidad para obtener información: en extraer sistemas de conocimiento especializado; en revelar códigos secretos de lenguaje y comunicación al interior de los mundos cotidianos y sobrenaturales; y, sobre todo, en hacer visible lo tácito, lo inherente, lo elusivo; en desarmar los secretos del extenso pasado" (en Manderson et al., 2015: 183).

Puede parecer que esto que hacemos los antropólogos se parece incómodamente a la labor de un hacker. La imagen ya la trabajó García Canclini (2006), sobre todo para plantear sus diferencias: en contraste con lo que él hace, nuestro conocimiento no se deriva de la obtención astuta de una clave, sino de la familiarización prolongada con redes complejas de interacciones y significados, de la cercanía e intimidad que se establece con los interlocutores.

31 Basta si no pensar en toda la información que puede revelarnos una simple charla de ascensor en contraposición a una entrevista pautada, donde el interlocutor, por múltiples motivos, se limita a repetir informaciones tan formales como vacías. 
Las discrepancias no se agotan allí: si bien es cierto que el trabajo de campo implica una labor de indagación que puede hermanarnos, a los ojos de nuestros interlocutores, con otros oficios ${ }^{32}$, la búsqueda y el sentido último de la información que construimos nos aleja al mismo tiempo de estas otras actividades. La antropología no busca verdades sino discursos, no presupone datos externos sino informaciones construidas, no descubre hechos ni asigna responsabilidades. Bucea, por el contrario, en explicaciones y significados de prácticas sociales (Sirimarco, 2012).

Todo lo cual no obsta para que las personas en el campo sigan adjudicándonos otros perfiles, siempre en líneas similares a la del hacker: desde "intrusos profesionales" hasta "vampiros de experiencias", pasando, ya más abiertamente, por la conocida figura del "espía chismoso" (Viñuales, 2000; García Canclini, 2006) 33. Las $^{33}$ referencias no pueden ser más sugerentes, y nos devuelven de lleno a los ejes de este trabajo, revelándonos cuán cerca parece estar la práctica antropológica, del género del chisme. No solo por las materias que abordamos - ¿cuántas veces somos acusados de interesarnos en minucias y "banalidades"? - como por el cariz de los modos en que conocemos.

Esta apreciación, que es válida para el trabajo de campo, parece sin embargo quebrarse cuando la investigación cristaliza en el texto etnográfico. Reconocemos que el trabajo de campo es un encuentro dialógico e intersubjetivo, pero luego establecemos jerarquizaciones entre el discurso del campo y el discurso disciplinario, objetivando ese encuentro en los textos que escribimos (Mannheim y Tedlock, 1995). Dejando de lado aquella información que resulta legal o éticamente comprometida para ser contenida en letra de molde, parecemos atribuir grados de decibilidad a la información que construimos, tamizando diferencialmente nuestros datos según sus condiciones de producción y nublando en el proceso los fundamentos mismos sobre los que producimos la información en el campo.

Si la clave del trabajo de campo es prestarle atención, como quería Malinowski (1986), a lo que la gente dice que hace o, como quería Geertz (1987), a rescatar lo dicho, entonces toda pieza comunicativa que escuchamos en el terreno habla de sucesos, modos y relaciones. Toda pieza comunicativa, ya sea una locución voluntaria o un comentario en voz baja, es una interpretación de la persona sobre el mundo. Y es justamente para eso que el antropólogo está en el campo: para ver lo que se hace y escuchar lo que se dice. Después de todo, el chisme no es más que la medida de nuestro conocimiento: si no conocemos sus escándalos — se recodará a Gluckman—, no conocemos la comunidad.

Parecemos seguir pensando, sin embargo, que algunas informaciones tienen raíces turbias, como si aun fuera posible moverse epistemológicamente entre lo público y lo privado - entre lo objetivo y lo subjetivo, la etnografía y el diario de campo, el dato y el chisme-, desconociendo el hecho de que construimos textos ostensiblemente científicos a partir de experiencias claramente biográficas (Geertz, 1989).

32 Mucho se ha tematizado acerca de las contigüidades existentes entre distintas clases de indagadores profesionales: detectives, analistas, jueces, abogados, antropólogos, inquisidores. Para una mayor profundización en este eje, ver Daich y Sirimarco (2009) y Sirimarco (2012).

33 En una postura más radical, fue el mismo Gluckman quien llamó la atención sobre la vinculación entre antropología y chisme. En un texto clásico sobre chisme y escándalo, señaló que el diccionario griego no definía al antropólogo como un "anthropos más logos" — un "estudioso del hombre"-, sino sólo como un "chismoso". Y remataba con una frase confirmatoria que Aristóteles hacía aparecer en su Ética Nicomaquea para referirse al gran hombre espiritual: "no es chismoso (anthropologos): no hablará sobre sí mismo ni sobre otra persona" (1963: 314). 
Llegados a este punto final, no quisiera ser malentendida. No estoy abogando aquí por la inclusión ingenua y desenfrenada de todo material en las etnografías que publicamos. Tampoco por la ventilación de asuntos sensibles y/o comprometedores que nada importan al desarrollo de la investigación. Lo que he intentado hasta aquí es simplemente colocar un interrogante: si durante el trabajo de campo producimos datos múltiples y variados, ¿existe acaso alguna pretensión de "pureza" epistemológica que nos incita a dejar de lado a algunos en base a exigencias de verdad y corroboración que sin duda no exigimos de otros? ¿Desestimamos ciertos datos por ser chismes o los rubricamos de ese modo para legitimar su rechazo?

Estas cuestiones no son preguntas retóricas, sino dudas concretas a las que el caso de Suárez me expuso. No estuve ni estoy a salvo de ellas, como queda en evidencia a partir de lo narrado. Pues no fue hasta que pasó el tiempo, la prensa confirmó la posible vinculación de Suárez en el caso y la justicia falló en consecuencia, que pude permitirme pensar lo que me habían comentado como la pieza discursiva (es decir construida, verosímil, falseable, interpretable) que siempre había sido. Sin una condena judicial en firme que confirmara y volviera público y narrable el episodio, tal vez esta mirada retrospectiva no hubiera sido posible.

Huelga decir que los argumentos aquí desarrollados no pueden entenderse por fuera de este caso y sus características. Otros casos, con sus particularidades y sensibilidades, deberán ser revisados a la luz de sus propias complejidades éticas. Pues lejos de pretender alzar generalizaciones, lo que he intentado en este trabajo ha sido interrogar no la materia del chisme sino su estatus y, con ello, las tensiones subyacentes al modo en que construimos lo decible y lo indecible en la etnografía como texto.

\section{Referencias bibliográficas}

Abrahms, R. (1970). "A Performance-Centred Approach to Gossip", Man, 5: 290-301.

- (1971). "Sense and nonsense in St. Vincent: speech behavior and decorum", American Anthropologist, 73: 762-772.

Bruner, Jerome (1991). "The narrative construction of reality", Critical Inquiry 18: 1-21.

- (1998). "What is a narrative fact?", The Annals of the American Academy of Political and Social Science, 560: 17-27.

Calandrón, Sabrina (2014). Género y sexualidad en la Policía Bonaerense. San Martín: Unsam Edita.

Carr, David (1986). "Narrative and the real world: an argument for continuity", History and Theory 25: 171-131.

Daich, Deborah y Sirimarco, Mariana (2009). “Anita anota. El antropólogo en la aldea (penal y burocrática)", Cadernos de campo, 18: 13-28.

- (2014). "Policías y prostitutas: el control territorial en clave de género", Revista Publicar, XII: 27-45.

Echegaray, Eduardo (1887). Diccionario general etimológico de la lengua española. Madrid: José María Faguineto editor.

Epstein, A.L. (1969). "Gossip, Norms and Social Network", en J.C. Mitchell (Ed.) Social Networks in Urban Situations. Manchester: Manchester University Press, 117-127.

Fasano, Patricia (2008). El chisme: una práctica que performatiza la sociabilidad del barrio. IX Congreso Argentino de Antropología Social. Universidad Nacional de Misiones. 
Fasano, Patricia, Ruiu Aurora, Gimenez Juan M. Giménez et.al. (2009). "El sentido del chisme en una comunidad de pobres urbanos", Ciencia, Docencia y Tecnología, 39: 4985.

Fonseca, Claudia (2000). Familia, fofoca e honra. Porto Alegre: Editora da UFRGS.

Frederic, Sabina (2008). Los usos de la fuerza pública. Debates sobre militares y policías en las ciencias sociales de la democracia. Buenos Aires: Biblioteca Nacional- Universidad Nacional de General Sarmiento.

García Canclini, Néstor (2006). ¿Dónde está la caja de herramientas? Cambios culturales, jóvenes y educación. Seminario internacional: La formación docente en los actuales escenarios: desafíos, debates, perspectivas. Universidad de La Matanza.

Geertz, Clifford (1987). La interpretación de las culturas. España: Gedisa.

- (1989). El antropólogo como autor. Barcelona: Editorial Paidós.

Gluckman, Max (1963). "Gossip and Scandal", Current Anthropology, 4: 307-316.

Lees, Sue (1989). "Learning to love: sexual reputation, morality and the social control of girls", en Maureen Cain (ed.) Growing up good: policing the behavior of girls in Europe. California: Sage Publications: 19-37.

Lowry, Ritchie P. (1980). "Toward a sociology of secrecy and security systems", en Stanton K. Tefft (ed.) Secrecy: a cross-cultural perspective. New York: Human Science, 297-316.

Malinowski, Bronislaw (1986). Los argonautas del Pacífico Occidental. Barcelona: PlanetaAgostini.

Manderson, Leonore, Davis Mark, Colwell Chip et.al. (2015). “On Secrecy, Disclosure, the Public, and the Private in Anthropology", Current Anthropology, 56: 183-190.

Mannheim, Bruce y Tedlock, Dennis (1995). The dialogic emergence of culture. Chicago: University of Illinois Press.

Martínez, Josefina y Eilbaum, Lucía (1999). "La violencia policial en Argentina. Una debate sobre las visiones del problema y las políticas posibles", en Proyecto Policía y Sociedad Democrática. CELS, Viva Rio-ISER, CED.

Neiburg, Federico (2003). "Intimidad y Esfera Pública. Política y cultura en el espacio nacional argentino", Desarrollo Económico. Revista de Ciencias Sociales, 170: 287-303.

Ochs, Elinor y Capps Lisa Capps (1996). "Narrating the self”, Annual Review of Anthropology, 25: 19-43.

Pita, María Victoria (2010). Formas de morir y formas de vivir. El activismo contra la violencia policial. Buenos Aires: Editores del Puerto \& CELS.

Reynoso, Carlos (1991). El surgimiento de la Antropología posmoderna. México: Editorial Gedisa.

Sain, Marcelo (2008). El Leviatán azul. Policía y política en la Argentina. Buenos Aires: Siglo XXI Editores.

Sarrabayrouse Oliveira, María José y Villalta Carla (2004). De “menores" al "Camarón”: itinerarios, continuidades y alianzas en el Poder Judicial. II Congreso Nacional de Sociología. Universidad de Buenos Aires.

Sirimarco, Mariana (2009). De civil a policía. Una etnografía del proceso de incorporación a la institución policial. Buenos Aires: Teseo.

- (2010). "Introducción”, en Mariana Sirimarco (Comp.) Estudiar la policía. La mirada de las ciencias sociales sobre la institución policial. Buenos Aires: Teseo, 9-25.

- (2012). "El policía y el etnógrafo (sospechado). Disputa de roles y competencias en un campo en colaboración”, Etnográfica, 16: 269-290.

- (2015). "Chonino: la conversión de una historia en narrativa. Relato y emoción en el ámbito policial argentino", Revista Anthropos, 110: 383-396. 
Stoler, Ann Laura (1992). "“In Cold Blood': Hierarchies of Credibility and the Politics of Colonial Narratives", Representations, 37: 151-189.

Tefft, Stanton K. (1980). "Secrecy, disclosure, and social theory", en: Stanton K. Tefft (Ed.) Secrecy: a cross-cultural perspective. New York: Human Science, 35-74.

Tiscornia, Sofía (1998). "Violencia policial. De las prácticas rutinarias a los hechos extraordinarios", en: Izaguirre, I. (Comp.) Violencia social y derechos humanos. Buenos Aires: Eudeba, 125145.

- (2008). Activismo de los derechos humanos y burocracias estatales. El caso Walter Bulacio. Buenos Aires: Editores del Puerto \& CELS.

Vaan Manen, John (1978). "Watching the watchers", en: Peter K. Manning y John Van Maanen (Eds.) Policing: A View from the Streets. California: Goodyear Publishing Company, 309350.

Van Vleet, Krista (2003). "Partial theories. On gossip, envy and ethnography in the Andes". Etnpgraphy, 4: 491-519.

Viñuales, Olga (2000). Identidades Lésbicas. Discursos y prácticas. Barcelona: Ed. Bellaterra. 2000. 